\title{
Identificação dos espaços livres e aplicação de indicadores para análise de praças ${ }^{1}$
}

\section{Identification of open spaces and use of indicators to analyze squares}

\section{Wolkart, Isabella1; Conde, Karla Moreira2; Jesus, Luciana Aparecida Netto3; Ramos, Larissa Andara 4}

1 Universidade Federal do Espírito Santo, Vitória/ES, Brasil. isabellawolkart@gmail.com²

2 Universidade Federal do Espírito Santo. karla.conde@ufes.br

3 Universidade Federal do Espírito Santo. Iuciana.a.jesus@ufes.br

4 Universidade Vila Velha. larissa.ramos@uvv.br

\begin{abstract}
RESUMO
O presente artigo é parte integrante de pesquisa intitulada "Identificação de áreas de convívio público e áreas verdes do município de Vitória/ES", desenvolvida em parceria entre a Universidade Federal do Espírito Santo e a Universidade Vila Velha/ES. Este artigo apresenta a avaliação da qualidade das praças da Regional 9 - Jardim da Penha, Vitória - ES, por meio de indicadores. Para tal, as áreas verdes e espaços livres de uso público nos 6 bairros que compõem a Regional 9 foram identificados e classificados. Os indicadores utilizados pela pesquisa foram selecionados e adaptados do Índice de Caminhabilidade (iCam) e elaborados e organizados pelo grupo de pesquisa em 4 categorias para aplicação em praças, são elas: Proteção e Segurança; Conforto e Imagem; Acessos e Conexões; e Sociabilidade, Uso e Atividades, estas foram subdivididas em 11 atributos e 34 indicadores. Com classificação por pontuação de 0 a 3, "insuficiente" a "ótimo". Paralelamente, a partir do Sistema de Informação Geográfica (SIG), no software ArcGis (versão 10.4.1), foram mapeados os espaços livres e elaborados mapas e figuras utilizando imagens de satélite. As praças da regional obtiveram resultados gerais "bom" e "suficiente", entretanto, alguns atributos obtiveram resultados insatisfatórios.
\end{abstract}

Palavras-chave: espaço livre, área verde, praça e indicador.

\footnotetext{
ABSTRACT

The present study is part of the research entitled "Identification of public living areas and green areas of the city of Vitória (ES)", developed by a collaborative research network between the Federal University of Espírito Santo and Vila Velha University. This article presents an evaluation

${ }^{1}$ WOLKART, Isabella; KONDE, Karla; JESUS, Luciana; RAMOS, Larissa. Identificação dos espaços livres e aplicação de indicadores para análise de praças. In: II SIMPÓSIO NACIONAL DE GESTÃO E ENGENHARIA URBANA: SINGEURB, 2019, São Paulo. Anais... Porto Alegre: ANTAC, 2019.
} 
of the quality of the squares of Regional 9 - Jardim da Penha, Vitória-ES, through indicators. To this end, as the green areas and open spaces of public use in the 6 districts that make up a Regional 9 were identified and classified. The indicators were selected and adapted for the Walkability Index (iCam) and elaborated and organized by the research group into 4 categories for the application in plazas, which are: Protection and Safety; Comfort and Image; Access and Connections; and Sociability, Use and Activities, were subdivided into 11 attributes and 34 indicators. With the scoring parameter from 0 to 3 , "insufficient" to "optimal." At the same time, from the Geographic Information System (GIS) in ArcGis software, free spaces and elaborated maps and figures were mapped from satellite images. The regional squares are generally "good" and "sufficient", however, some attributes are unsatisfactory.

Keywords: open space, green area, square, indicator.

\section{INTRODUÇÃO}

As áreas verdes e os espaços livres são as fronteiras do traçado urbano que visam à salubridade do meio (MEIRELLES, 2007 apud Paula, 2014). Dentro dessa concepção, toda área verde é um espaço livre, porém, os espaços livres são considerados áreas verdes quando não impermeabilizados e/ou com significativa cobertura vegetal (MILANO,1992). Espaços livres podem ser definidos como espaços urbanos ao ar livre, destinado a todo tipo de utilização que se relacione com caminhadas, descanso, passeios, práticas de esporte e, em geral, à recreação e ao entretenimento (CAVALHEIRO, F. et al., 1999).

Em pesquisa intitulada "Identificação de áreas de convívio público e áreas verdes dos municípios de Vitória-ES" da Universidade Federal do Espírito Santo (UFES), em parceria com o grupo de pesquisa "Paisagem Urbana e Inclusão" da Universidade Vila Velha (UVV), foram selecionados indicadores para avaliação de praças, tendo como principal referência bibliográfica o Índice de Caminhabilidade (iCam) (ITDP, 2018). A pesquisa identifica e classifica dentro do cenário urbano os espaços livres de uso público a fim de avaliar e comparar os resultados obtidos em regionais administrativas de Vitória e Vila Velha.

Este artigo avalia a qualidade das praças da Regional 9 - Jardim da Penha, Vitória-ES, por meio de indicadores organizados em 4 categorias, são elas: "Proteção e Segurança", "Conforto e Imagem", "Acessos e Conexões" e "Sociabilidade, Usos e Atividades".

De acordo com a Lei $n^{\circ} 8.611 / 2014$ a Regional 9 compõe-se de seis bairros, sendo estes: Boa Vista, Jardim da Penha, Mata da Praia, Morada de Camburi, Pontal de Camburi e República. A região detém a segunda maior população do Estado e é a sétima em área e em densidade demográfica, apresentando cerca de 48.000 habitantes e $3.665 \mathrm{~km}^{2}$ (IBGE, 2010).

\section{METODOLOGIA}

Com base no levantamento teórico, foi definida a forma de avaliação do objeto de análise, as praças.

O iCam define duas unidades básicas para a coleta de dados, as "categorias" e os "indicadores". As categorias apresentadas no iCam foram renomeadas neste trabalho como "atributos" e organizadas com base no Guia do espaço público para inspirar e transformar (HEEMANN; SANTIAGO, 2015).

Assim, foram organizados: categorias, atributos e indicadores. As "categorias" são o conjunto de critérios utilizados para avaliar um determinado assunto, tema ou objeto; os "atributos", termo que qualifica as categorias; e os "indicadores" avaliam, de forma unitária, o desempenho do objeto analisado (CONDE et al., 2019).

Foram selecionados indicadores do índice de Caminhabilidade - iCam (ITDP, 2018), elaborado pelo Instituto de Políticas de Transporte e Desenvolvimento - ITDP Brasil, considerando as adaptações necessárias para a aplicação em praças e incluídos outros indicadores julgados necessários pelo grupo de pesquisa. Os 34 indicadores foram organizados em 11 atributos e subdivididos em 4 categorias. 
O quadro 1 apresenta as categorias, os atributos e os indicadores analisados, sendo destacados em cinza os indicadores apresentados pelo ITDP (ITDP, 2018), seguindo os parâmetros, equipamentos e observações estabelecidos pelo mesmo.

Quadro 1-Categorias, atributos e indicadores analisados

\begin{tabular}{|c|c|c|}
\hline Categoria & Atributo & Indicador \\
\hline \multirow{10}{*}{$\begin{array}{l}\text { A. Proteção e } \\
\text { Segurança }\end{array}$} & \multirow{2}{*}{ A.1. Segurança Viária } & A.1.1. Travessias \\
\hline & & A.1.2. Tipologia da Rua \\
\hline & \multirow{4}{*}{ A.2. Segurança Pública } & A.2.1. Iluminação \\
\hline & & A.2.2. Eficiência Energética \\
\hline & & A.2.3. Fluxo de Pedestres Diurno e Noturno \\
\hline & & A.2.4. Câmeras de Segurança \\
\hline & \multirow{4}{*}{ A.3. Proteção Física } & A.3.1. Localização do Espaço para Brincar \\
\hline & & A.3.2. Material do Piso da Área Infantil \\
\hline & & A.3.3. Material dos Brinquedos Infantis \\
\hline & & A.3.4. Estado de Conservação dos Brinquedos \\
\hline \multirow{8}{*}{$\begin{array}{l}\text { B. Conforto e } \\
\text { Imagem }\end{array}$} & \multirow{4}{*}{ B.1. Ambiente } & B.1.1. Coleta de Lixo \\
\hline & & B.1.2. Polvição Sonora \\
\hline & & B.1.3. Sombra e Abrigo \\
\hline & & B.1.4. Sombra e Abrigo em Área Específica \\
\hline & \multirow{3}{*}{$\begin{array}{l}\text { B.2. Áreas Verdes/ } \\
\text { Cobertura Vegetal }\end{array}$} & B.2.1. Área de Sombra de Copa de Árvore \\
\hline & & $\begin{array}{c}\text { B.2.2. Área de Sombra de Copa de Árvore em Área } \\
\text { Específica }\end{array}$ \\
\hline & & B.2.3. Cobertura Vegetal \\
\hline & B.3. Espaços para Sentar & B.3.1. Assentos \\
\hline \multirow{6}{*}{$\begin{array}{l}\text { C. Acessos e } \\
\text { Conexões }\end{array}$} & \multirow{3}{*}{ C.1. Mobilidade } & C.1.1. Dimensão das Quadras \\
\hline & & C.1.2. Distância a Pé ao Transporte Público \\
\hline & & C.1.3. Paraciclo/ Bicicletário \\
\hline & \multirow{3}{*}{$\begin{array}{l}\text { C.2. Calçada e } \\
\text { Pavimentação }\end{array}$} & C.2.1. Largura da Calçada \\
\hline & & C.2.2. Pavimentação da Calçada \\
\hline & & C.2.3. Pavimentação da Praça \\
\hline \multirow{10}{*}{$\begin{array}{l}\text { D. Sociabilidade, } \\
\text { Usos e Atividades }\end{array}$} & \multirow{4}{*}{ D.1. Atração } & D.1.1. Fachadas Fisicamente Permeáveis \\
\hline & & D.1.2. Fachadas Visualmente Ativas \\
\hline & & D.1.3. Uso Noturno e Diurno \\
\hline & & D.1.4. Uso Misto \\
\hline & \multirow{3}{*}{$\begin{array}{l}\text { D.2. Equipamentos e } \\
\text { Atividades }\end{array}$} & D.2.1. Equipamentos Fixos e Serviços \\
\hline & & D.2.2. Apropriações Comunitárias \\
\hline & & D.2.3. Atividades que Incluem Idosos \\
\hline & \multirow{3}{*}{$\begin{array}{l}\text { D.3. Estímulos Motores e } \\
\text { Sensoriais }\end{array}$} & D.3.1. Estímulos Motores \\
\hline & & D.3.2. Estímulos Sensoriais/ Lúdicos \\
\hline & & D.3.3. Brincadeiras de Regras \\
\hline
\end{tabular}

Ainda com base no iCam (ITDP, 2018), foram estabelecidas quatro pontuações que qualificam a praça em: ótimo, bom, suficiente e insuficiente, onde cada pontuação equivale a um parâmetro de qualidade para o indicador (Quadro 2).

Quadro 2 - Pontuações dos indicadores

\begin{tabular}{|c|c|c|c|}
\hline Pontuação 3 & Pontuação 2 à 2,9 & Pontuação 1 à 1,9 & Pontuação 0 à 0,9 \\
\hline Ótimo & Bom & Suficiente & Insuficiente \\
\hline
\end{tabular}

Fonte: Adaptado do iCam (ITDP, 2018)

Paralelamente a seleção de indicadores e o estabelecimento dos parâmetros para avaliação, foi utilizado o Sistema de Informação Geográfica (SIG), no software ArcGis (versão 10.4.1), para mapear os espaços livres de uso público. Foram identificados, com base no mapeamento realizado pela Prefeitura Municipal de Vitória (PMV), todos os espaços livres de uso público da regional e distinguidos os parques urbanos, a orla da Praia de Camburi e as praças, este último para análise. 
Foram considerados praças os espaços livres de uso público maiores do que $450 \mathrm{~m}^{2}$ (BUCCHERI FILHO; $\mathrm{NUCCl}$ 2006), e que apresentam um ou mais equipamentos fixos para realização de atividades relacionadas ao lazer. Definiu-se, os raios de influência dos parques e praças, sendo de 1.000 metros (KLIASS, 1993) e 400 metros (HANNES, 2016), respectivamente.

Para avaliação dos indicadores, foram realizadas duas visitas de aproximadamente 30 minutos em cada praça, no mês de janeiro de 2019, durante as visitas cada praça foi pontuada de acordo com os parâmetros de cada indicador. A pontuação por atributo é a média aritmética dos indicadores pertencentes a cada atributo, a pontuação por categoria é a média aritmética dos indicadores da categoria e a pontuação geral é a média da pontuação das categorias. Os resultados permitem qualificar e indicar as deficiências de cada praça, do bairro e/ou da regional.

Este artigo identifica os espaços livres de uso público da Regional 9 - Jardim da Penha, Vitória (ES), e aplica a metodologia de análise nas praças acima de $450 \mathrm{~m}^{2}$.

\section{IDENTIFICAÇÃO DOS ESPAÇOS LIVRES DE USO PÚBLICO}

Na Regional 9 - Jardim da Penha, Vitória (ES), foram identificados os espaços livres de uso público. Dentre estes, estão o calçadão da Praia de Camburi, 2 parques urbanos - Parque Pedra da Cebola e Parque Pe. Alfonso Pastore (formado por 5 praças), totalizando 13 praças acima de $450 \mathrm{~m}^{2}$ (figura 1).

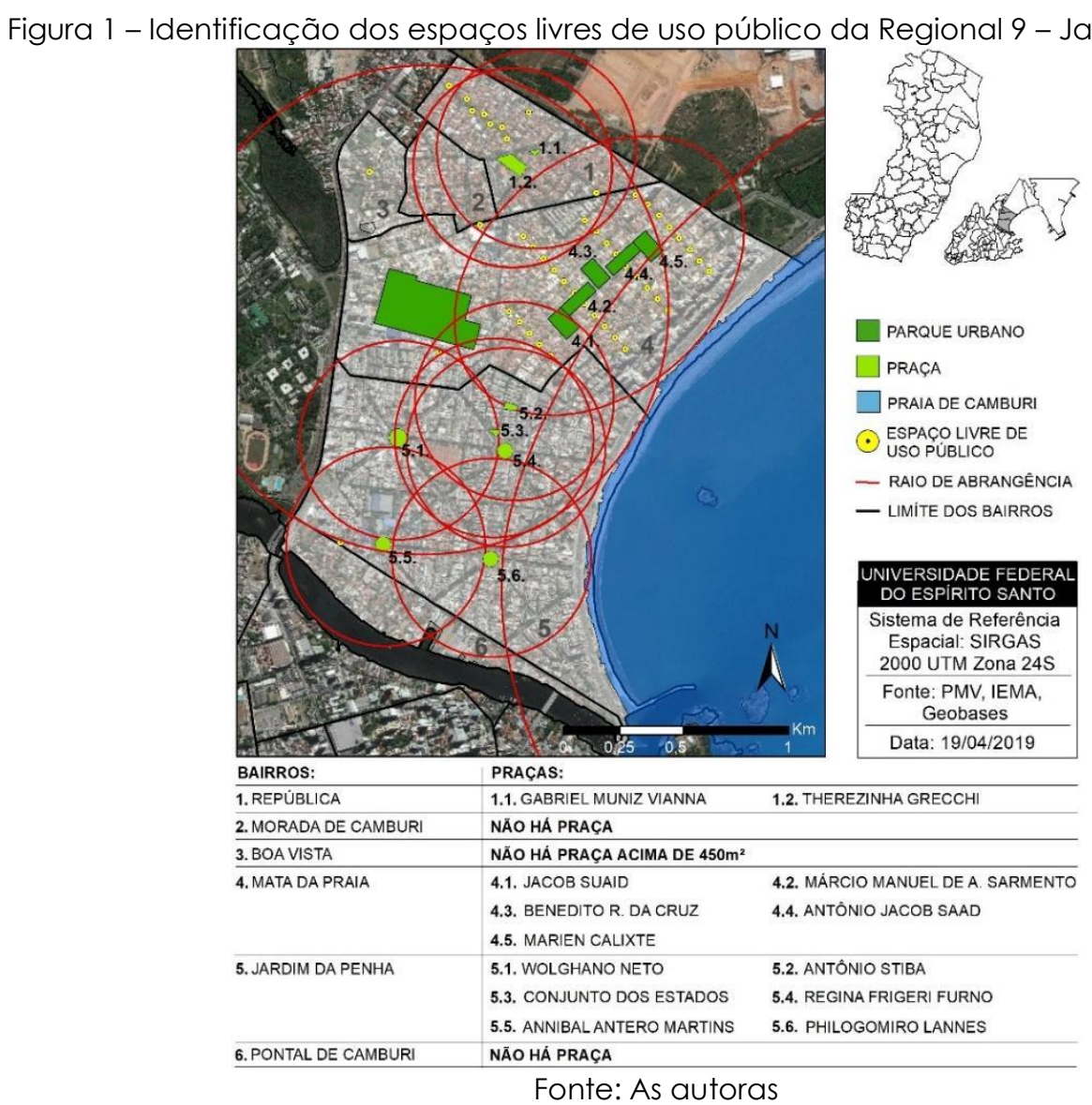

Observa-se na figura 1 que apenas três bairros da regional possuem praças ou parques, são: República (1), Mata da Praia (4) e Jardim da Penha (5). Por outro lado, observando o raio de abrangência, conclui-se que praticamente toda a regional é atendida por praças e/ou parques, apesar de Morada de Camburi (2) e Pontal de Camburi (6) não possuírem espaços de uso público, e Boa Vista (3) não possuir espaços de uso público com áreas superiores a $450 \mathrm{~m}^{2}$. 
A Regional 9 - Jardim da Penha possui dois parques urbanos, o Parque Pedra da Cebola, e o Parque Padre Alfonso Pastore. Foi adotado o raio de 1.000 metros para o Parque Pedra da Cebola e de 400 metros para cada uma das praças que formam o Parque Padre Alfonso Pastore, pois apesar de também ser considerado um Parque Urbano pela Prefeitura Municipal de Vitória, os conceitos estabelecidos pelo grupo de pesquisa sobre tipos de espaços livres públicos e áreas verdes o classifica como praças. Devido a essa característica foi analisado em função de cada praça.

\section{APLICAÇÃO DOS INDICADORES}

Aplicando a metodologia obteve-se os resultados dos gráficos 1, 2, 3, 4, que apresentam a pontuação de cada atributo e a média da categoria por praça, e o gráfico 5 que apresenta a média geral de todas as categorias por praça e a pontuação final. Na horizontal estão identificadas as praças e na vertical as pontuações de 0 a 3 (insuficiente a ótimo) das diferentes categorias analisadas.

\section{Gráfico 1 - Categoria Proteção e Segurança}

\section{A. Proteção e Segurança}

3

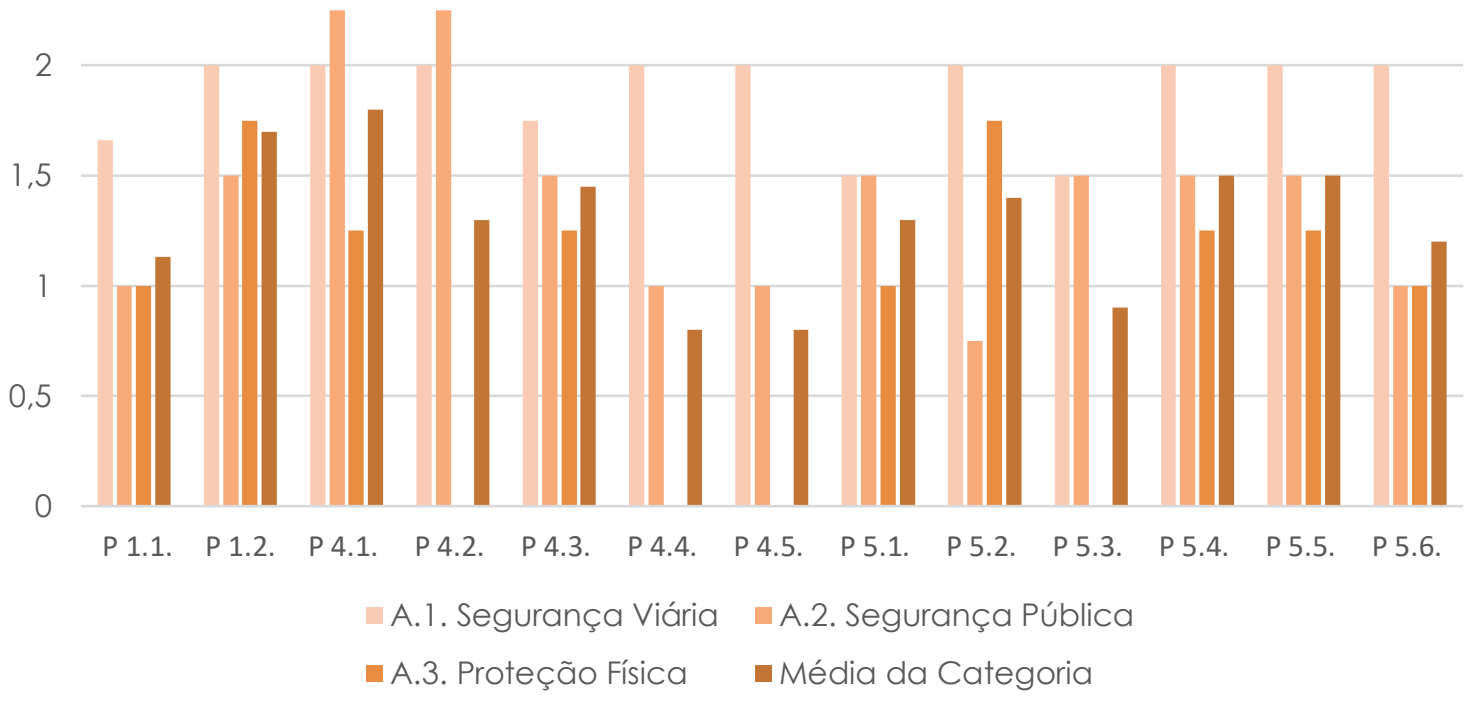

Fonte: As autoras 
Gráfico 2 - Categoria conforto e imagem

B. Conforto e Imagem

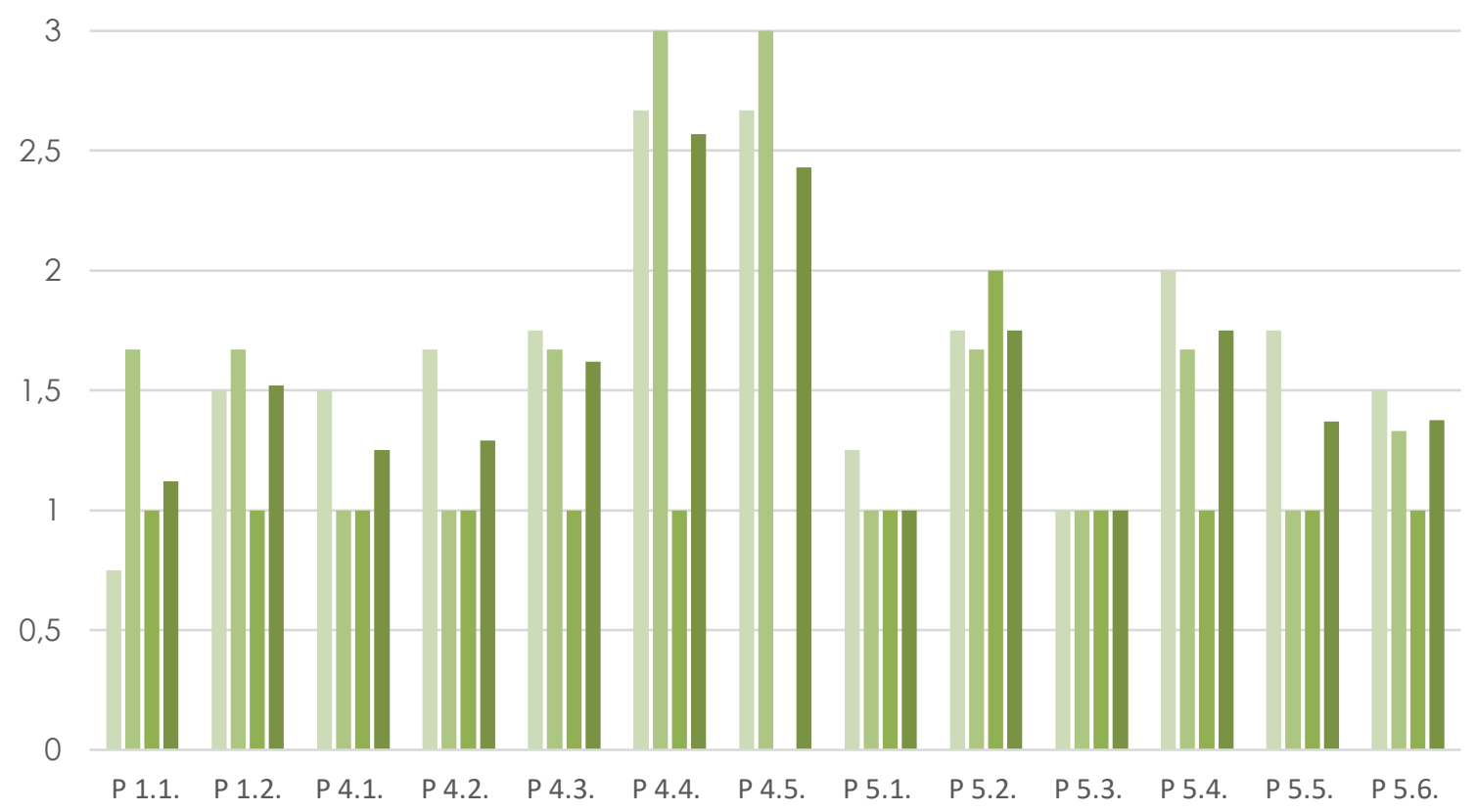

$\square$ B.1. Ambiente $\square$ B.2. Áreas Verdes/ Cobertura Vegetal $\square$ B.3. Espaços para Sentar $\square$ Média da Categoria

Fonte: As autoras

Gráfico 3 - Categoria acessos e conexões

C. Acessos e Conexões

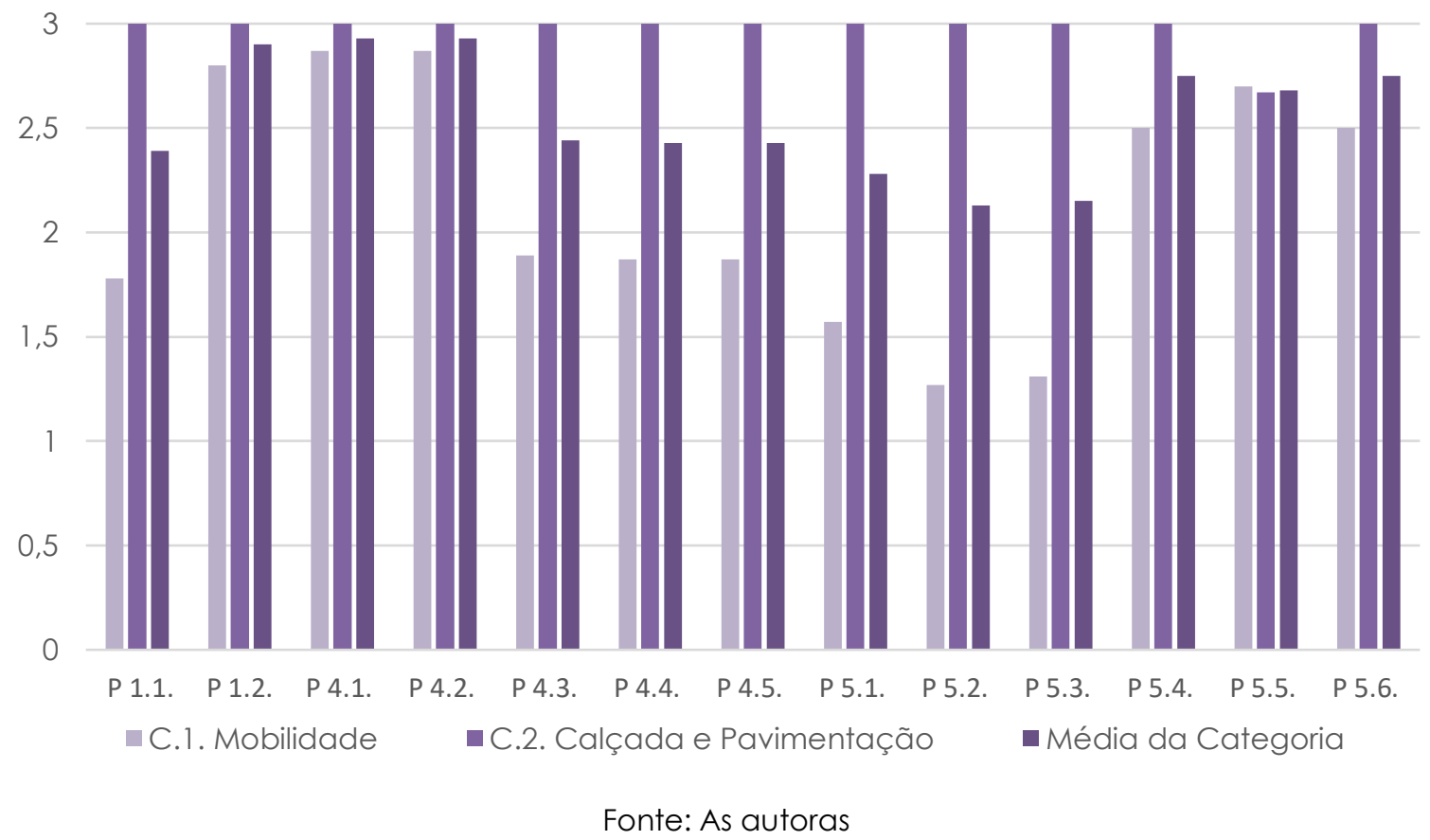


Gráfico 4 - Categoria sociabilidade, usos e atividades

D. Sociabilidade, Usos e Atividades

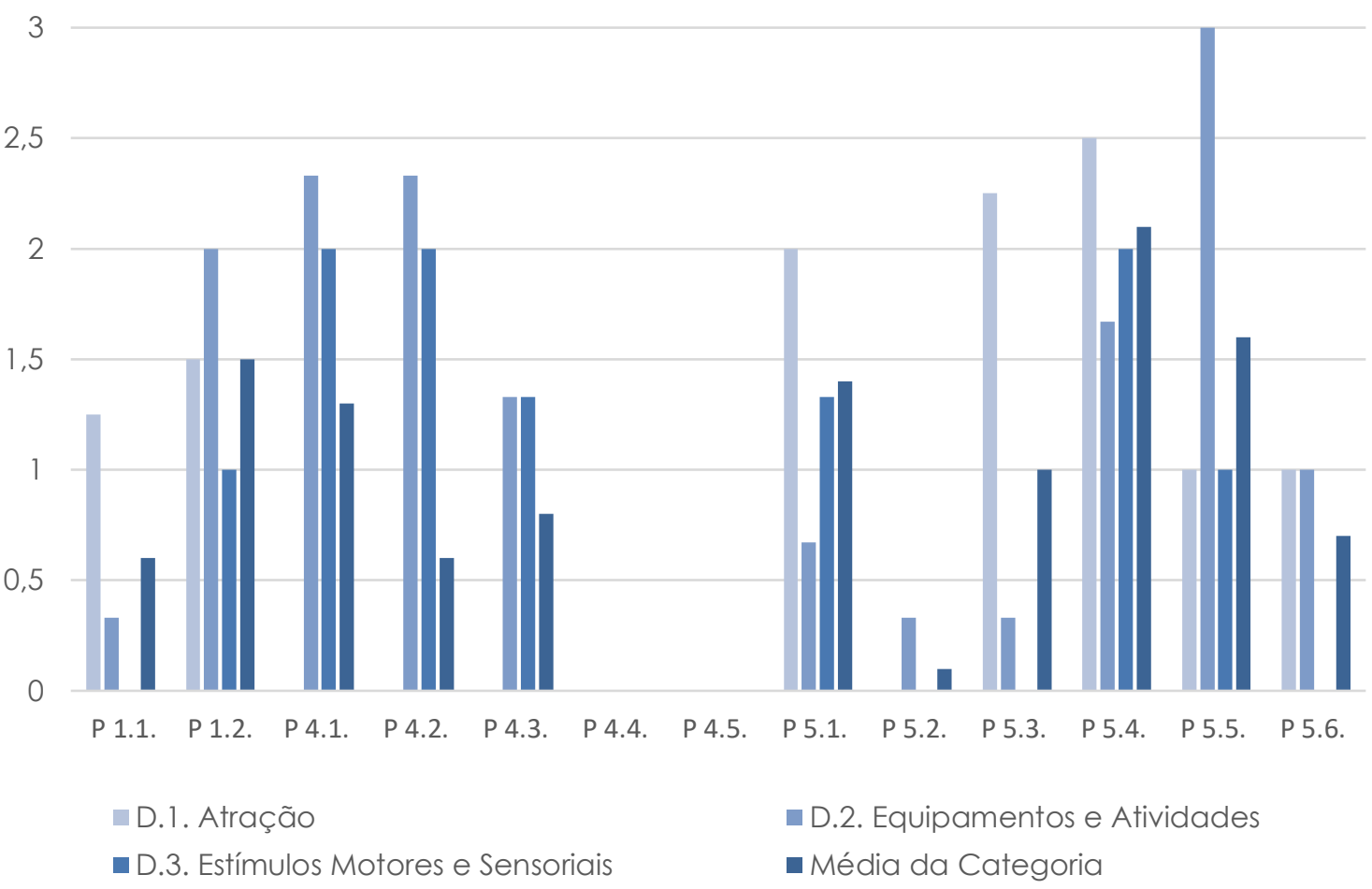

Fonte: As autoras

Gráfico 5 - Média de todas as categorias por praça

Média Geral

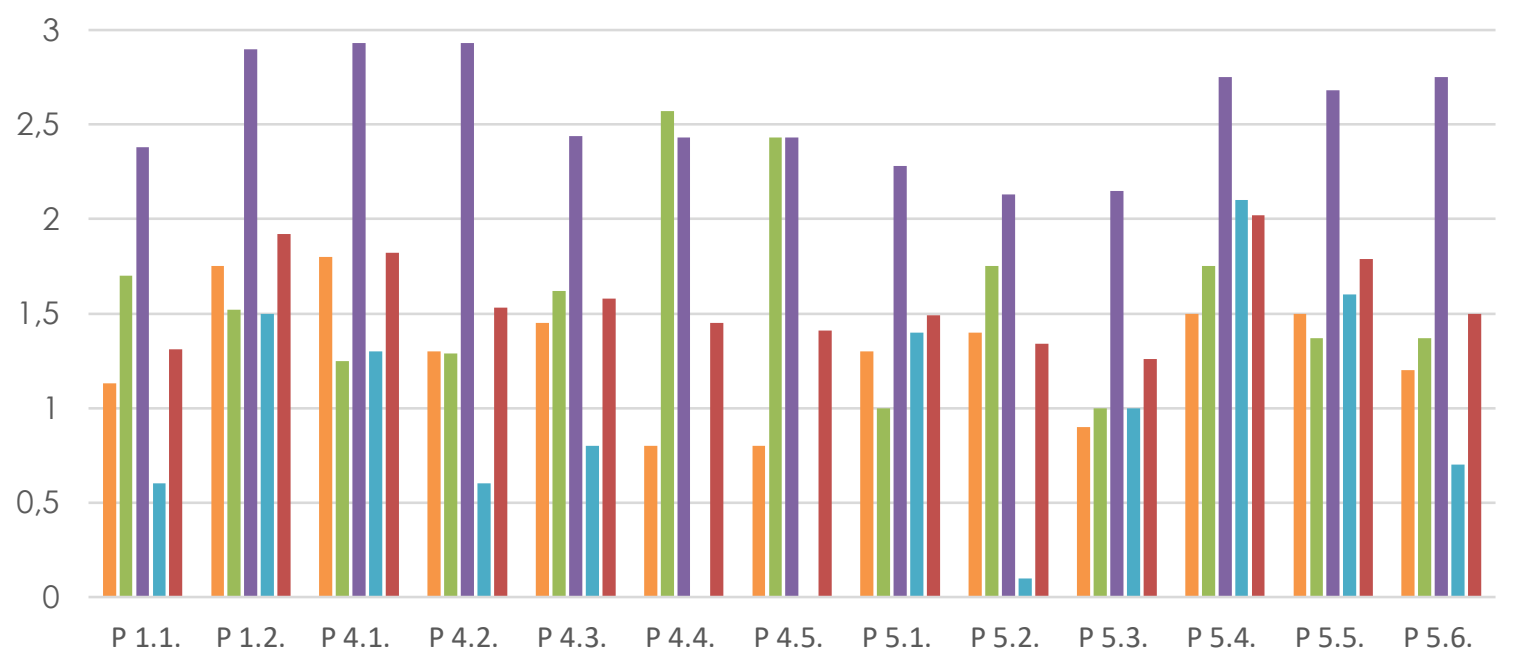

A. Proteção e Segurança

B. Conforto e Imagem

- C. Acessos e Conexões

D. Sociabilidade, Usos e Atividades

- Média Geral

Fonte: As autoras 
Os resultados foram satisfatórios, de forma geral (Gráfico 5), com a média das categorias variando entre 1,3 e 2, isto é, entre o considerado bom e suficiente. Entretanto, os resultados por categoria se destoam consideravelmente uns dos outros, apontando problemas de Proteção e Segurança e Sociabilidade, Usos e Atividades.

A categoria Proteção e Segurança (Gráfico 1) aponta problemas relacionados a proteção física no bairro Mata da Praia, onde apenas duas das praças possuem parquinhos, Jacob Suaid (P 5.1.) e Benedito da Cruz (P 5.3.), e receberam nota indiferente a 0 no atributo. Entretanto, as praças deste bairro são contíguas umas das outras (figura 1), separadas apenas por uma rua, portanto, a carência de uma pode ser suprida pela outra.

Conforto e Imagem (Gráfico 2) apresentou resultados, em geral, bons e suficientes, com apenas duas praças destoando das demais, são as praças Antônio Jacob Saad (P 4.4.) e Marien Calixte (P 4.5.), localizadas no Parque Padre Alfonso Pastore, na Mata da Praia. Estas são encobertas por vegetação e carentes em mobiliários, enquanto outras praças do parque apresentam características opostas.

A categoria Acessos e Conexões (Gráfico 3) se destacou pelo bom desempenho, em especial, no atributo calçada e pavimentação que atingiu a nota máxima em todas as praças.

O gráfico da categoria Sociabilidade, Usos e Atividades (gráfico 4) foi o mais irregular, com notas variando entre ótimo e insuficiente dentro de um mesmo atributo. A carência maior é com relação a atratividade na Mata da Praia, onde todas as praças são insuficientes. O atributo estímulos motores e sensoriais, mostrou resultados destoantes entre praças de um mesmo bairro, em Jardim da Penha e Mata da Praia, indicando a concentração de certos equipamentos e algumas praças específicas dos bairros.

\section{CONCLUSÃO}

Os resultados das avaliações mostram as qualidades e as deficiências de cada praça, o que colabora para o entendimento dos motivos que levam uma praça a ser apropriada pela população local ou sofrer abandono. Podendo ser utilizado como diretriz na elaboração projetos de espaços livres.

A Regional 9 - Jardim da Penha é bem atendida tanto quantitativamente quanto qualitativamente por parques urbanos e praças, com resultados gerais considerados "bons" e "suficientes". Os raios de abrangências mostram que praticamente toda a população é beneficiada por pelo menos um destes espaços livres, devido a distribuição e proximidade entre praças. Um espaço livre de uso público, muita das vezes, é capaz de suprir a demanda do outro, pela proximidade. O que deve ser considerado na análise dos resultados.

\section{AGRADECIMENTOS}

As autoras agradecem a FAPES - Fundação de Amparo à Pesquisa e Inovação do Espírito Santo que contribuíram com o desenvolvimento deste trabalho.

\section{REFERÊNCIAS}

BUCCHERI FILHO, A.T.; NUCCl, J.C. Open spaces, green areas and tree canopy coverage in the Alto da XV district, Curitiba/PR. Revista do Departamento de Geografia, n. 18, 2006. p. 4859.

CAVALHEIRO, F. et al. Proposição de Terminologia para o Verde Urbano. Boletim Informativo da Sociedade Brasileira de arborização urbana. SBAU: Ano VII, Rio de Janeiro, 1999.

CONDE, K.; ALVAREZ, C.E.; BRAGANÇA, L. Proposta de critérios e indicadores de avaliação de sustentabilidade urbana para países latino-americanos. In: EuroELECS 2019. III Encontro Latinoamericano Y Europeo sobre Edificaciones y Comunidades Sostenibles. Argentina, Libro 
de Actas... Santa Fe, Argentina, Maio 22-25, 2019 p.1412-1424.

HANNES, Evy. Espaços abertos e espaços livres: um estudo de tipologias. Paisagem e Ambiente: Ensaios - N. 37 - São Paulo, 2016. p.121 - 144.

HEEMANN, Jenifer; SANTIAGO, Caiuby. Guia do espaço público para inspirar e transformar. Mountain View (CA), USA, 2015.

IBGE. Instituto Brasileiro de Geografia e Estatística. CENSO DEMOGRÁFICO 2010.

Características da população e dos domicílios: resultados do universo. Rio de Janeiro: IBGE, 2010.

ITDP. Índice de Caminhabilidade. Ferramenta, Versão 2.0. Instituto de Políticas de Transporte e Desenvolvimento. Rio de Janeiro, 2018.

KLIASS, Rosa Grená. Parques Urbanos de São Paulo. São Paulo: Pini, 1993.

MAGNOLI, Miranda Martinelli. Projetos de Espaços Livres Urbanos. 1982. Tese (Pós-Doutorado em Arquitetura e Urbanismo) - Faculdade de Arquitetura e Urbanismo da Universidade de São Paulo, São Paulo, 1982.

MILANO, M. S. A cidade, os espaços abertos e a vegetação. In: ENCONTRO NACIONAL SOBRE ARBORIZAÇÃO URBANA, Vitória, 1992. Anais... Vitória: PMV, 1992.

PAULA, I. Análise dos espaços de uso público da cidade de Juiz de Fora (MG) com base no conceito de áreas verdes. Revista on-line - CAMINHOS DE GEOGRAFIA. Uberlândia, 2014, p. 160-174. 